\title{
Effect of Woodfordia fruticosa on dexamethasone induced insulin resistance in mice
}

\author{
Santosh S. Bhujbal," Clarine A. Providencia, Rabindra K. \\ Nanda, ${ }^{1}$ Sunita S. Hadawale, Rupesh R. Yeola
}

Department of Pharmacognosy, Padmashree Dr. D. Y. Patil Institute of Pharmaceutical Sciences and Research, India.
Revista Brasileira de Farmacognosia Brazilian Journal of Pharmacognosy 22(3): 611-616, May/Jun. 2012

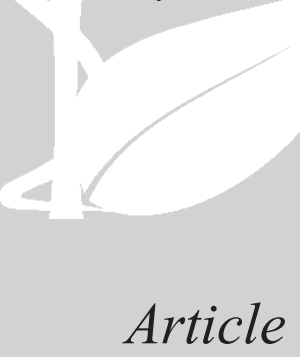

Article

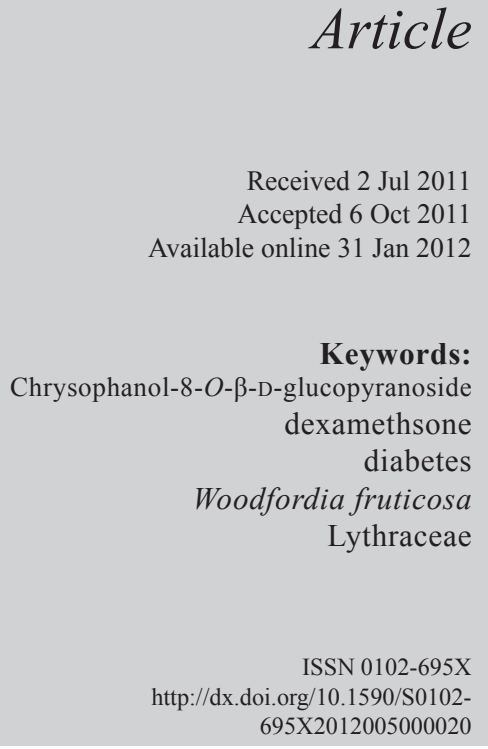

Received 2 Jul 201

Accepted 6 Oct 2011 2

ds:

-glucopyranoside diabetes fruticosa

(5)/S0102$695 \mathrm{X} 2012005000020$

\begin{abstract}
Diabetes is a group of syndrome characterized by hyperglycemia, altered metabolism of lipids, carbohydrates and proteins, resulting in an increased risk of complications from vascular disease. The flowers of Woodfordia fruticosa (L.) Kurz, Lythraceae, have been used traditionally in the treatment of diabetes, dysentery, diarrhea, other bowel complaints, internal haemorrhages, in leucorrhoea and menorrhagia. Externally powdered flower is sprinkled over foul ulcers and wounds for diminishing their discharge and promoting granulations. In Konkan leaves are used in bilious sickness. W. fruticosa is also reported to have DNA topoisomerase inhibitor, antibacterial, antifertility, antipeptic ulcer, free radical scavenging, and hepatoprotective activity. W. fruticosa is a medicinal plant used to treat a wide range of disorder including diabetes. The present work investigates the effects of the WF in dexamethsone induced insulin resistance in mice. The results of animal study revealed that the extract at dose 100, 200 and $400 \mathrm{mg} / \mathrm{kg}$ was found to be significant $(p<0.01)$ after 22 days of treatment. Further isolation studies afforded an anthraquinone glycoside, chrysophanol-8- $O-\beta-\mathrm{D}-$ glucopyranoside. Moreover further experiments will be required to identify their exact mechanism of action.
\end{abstract}

\section{Introduction}

Diabetes is a group of syndrome characterized by hyperglycemia, altered metabolism of lipids, carbohydrates and proteins, and an increased risk of complications from vascular disease (Goodman \& Gilman, 2001). It may occasionally arise secondarily from any disease causing extensive destruction of pancreatic islets, including pancreatitis tumors, certain drugs iron overload (hemochromatosis), certain acquired or genetic endocrinopathies, and surgical excision. However the most common and important forms of diabetes mellitus arise from primary disorders of the islet cell-insulin signaling system (Ramzi et al., 2000). Most patients can be classified clinically as having either type 1 diabetes mellitus (insulin dependent diabetes mellitus) or type 2 diabetes mellitus (Non insulin dependent diabetes mellitus). The number of people with diabetes is increasing due to population growth, aging, urbanization, and increasing prevalence of obesity and physical inactivity. In developing countries, the majority of people with diabetes are in the age range of 45 to 64 years. In contrast, the majority of people with diabetes in developed countries are $>64$ years of age. By 2030, it is estimated that the number of people with diabetes $>64$ years of age will be $>82$ million in developing countries and $>48$ million in developed countries (Wild et al., 2004). There are lots of chemical agents available to control and treat diabetic patients, but total recovery from diabetes has not been reported up to date. Alternatives to these synthetic agents, plants provide a potential source of antihyperglycemic drugs and are widely used in several traditional systems of medicine to prevent diabetes with less side effect and compatible with the physiological system. There is a constant attempt by scientists to understand the active principle present in medicinal plants with antidiabetic properties. Metformin, a less toxic biguanide and potent glucose lowering agent was developed from Galega officinalis and used to treat diabetes. Out of dozens of oral medications for diabetes, only one medication (metformin) is approved for use in children and it has been originated from herbs (Jerald et al., 2008). Thus there is a dire need to search for more phytoconstituents for the treatment of diabetes.

The flowers of Woodfordia fruticosa (L.) Kurz, Lythraceae, have been used traditionally in the treatment of diabetes, dysentery, diarrhea, other bowel complaints, internal haemorrhages, in leucorrhoea and menorrhagia. Externally powdered flower is sprinkled over foul ulcers and wounds for diminishing their discharge and promoting granulations. In Konkan leaves are used in 
bilious sickness (Nadkarni., 2009, Kunwar et al., 2009). The present communication reports the antidiabetic activity of the ethanolic extract of the leaves of $W$. fruticosa (WF) by employing dexamethasone induced insulin resistance in mice, along with the estimation of the lipidemic parameters. In addition to this, isolation of the compound that may be responsible for the said activity was also carried out.

\section{Material and Methods}

\section{Plant collection}

The leaves of Woodfordia fruticosa (L.) Kurz, Lythraceae, were collected from hilly areas in Aurangabad (India), and authenticated by Botanical Survey of India, Pune with a voucher specimen no. BSI/ WRC/Tech./2010/567. A herbarium was also deposited for future reference.

\section{Reagents}

Dexamethasone was procured from Cadila Pharmaceuticals Ltd. Pioglitazone, a standard antidiabetic agent was purchased from Sun Pharma Sikkim, India. Glucose, triacylglyceride and cholesterol kits were procured from Biolab Pvt. Ltd, India. All the chemicals and reagents were of analytical grade.

\section{Extraction and isolation}

The leaves of $W$. fruticosa (WF) were washed with water, shade dried and then powdered to an optimum size for extraction. The powdered drug (120 g) was extracted using Soxhlet apparatus with 95\% ethanol for about $36 \mathrm{~h}$. The extract was filtered and concentrated in vacuum under reduced pressure using rotary flash evaporator (Dan \& Dan, 1984). A dark green colored semisolid mass weighing $18.45 \mathrm{~g}(15.38 \% \mathrm{w} / \mathrm{w})$ was obtained. The extract $(1 \mathrm{~g})$ was taken into the minimum amount of methanol and was stirred until it gets well dissolved into the methanol and was filtered. Cold ether was slowly added into the filtrate and an anthraquinone glycoside $(0.35 \mathrm{~g})$ with a yield of $35 \%$ was obtained as yellowish brown powder which was then separated by filtration and dried under vacuum and subjected to spectral analysis (Bhujbal et al., 2010).

\section{Preliminary phytochemical screening}

The ethanol extract was subjected to qualitative chemical investigation for the identification of the phytoconstituents like sterols, triterpenoids, glycosides, alkaloids, carbohydrate and flavonoids (Khandelwal, 2004). The preliminary phytochemical analysis was also carried out using thin layer chromatography (TLC). The TLC analysis was performed on precoated silica gel plates $\mathrm{F}_{254}$, developed with a mixture of $\mathrm{CHCl}_{3}$ :glacial $\mathrm{CH}_{3} \mathrm{CO}_{2} \mathrm{H}: \mathrm{MeOH}: \mathrm{H}_{2} \mathrm{O}(64: 32: 12: 8)$ for saponins (Wagner \& Bladt, 2007), benzene:EtOAc (7:3) for triterpenoids (Klimek \& Tokar, 1998) and EtOAc:HCO $\mathrm{H}:$ glacial $\mathrm{CH}_{3} \mathrm{CO}_{2} \mathrm{H}: \mathrm{H}_{2} \mathrm{O}$ (100:11:11:26) for flavonoids. Spots were revealed by the anisaldehyde sulphuric acid reagent for saponins and triterpenoids and UV $365 \mathrm{~nm}$ for flavonoids.

\section{Animals}

Albino mice weighing 25-30 g were used for the study and were kept in animal house at $26 \pm 2{ }^{\circ} \mathrm{C}$ with relative humidity $44-56 \%$ along with light and dark cycles of $12 \mathrm{~h}$. Institutional Animal Ethics Committee has approved the experimental protocol (DYPIPSR/ IAEC/10-11/P-03). Animals were provided with standard diet and water ad libitum. The food was withdrawn 18-24 $\mathrm{h}$ before the start of the experiment.

\section{Experimental design}

Acute toxicity studies (OECD 425)

Healthy adult female Swiss albino mice weighing between 20 and $25 \mathrm{~g}$ body weights were selected for the acute toxicity study with the ethanolic extract of leaves of $W$. fruticosa (WF). The animals were fasted overnight prior to the experiment and maintained under standard conditions. The dose of $2000 \mathrm{mg} / \mathrm{kg}$ body weight was administered to the animals and were observed for any behavioral changes.

Dexamethasone-induced insulin resistance in mice

All the mice were weighed before treatment, group I (Normal Control) received equivalent amount of $0.9 \% \mathrm{w} / \mathrm{v}$ saline $(1 \mathrm{~mL} / \mathrm{kg}, p . o$.$) , and thirty mice$ were rendered hyperglycemic by daily administration of a prestandardised dose of dexamethasone (1 mg/ $\mathrm{kg}, i . m$.) for consecutive seven days and then divided into five groups of six each (Ghaisas et al., 2009). Group II (Dexa-control) continued to receive only dexamethasone for next fifteen days, group III received pioglitazone $(2 \mathrm{mg} / \mathrm{kg}$, p.o.) along with dexamethasone respectively for fifteen days. Groups IV, V, VI were treated with dexamethasone along with three different doses of WF 100, 200 and $400 \mathrm{mg} / \mathrm{kg}$, p.o. respectively for fifteen days. Simultaneously four other groups (groups VII, VIII, IX, and X), each with six normoglycemic animals, were administered equivalent amount of pioglitazone and three different doses of WF 
100,200 and $400 \mathrm{mg} / \mathrm{kg}$, p.o., respectively. On the $0^{\text {th }}$, $8^{\text {th }}, 15^{\text {th }}$ and $22^{\text {nd }}$ day blood samples were collected and treated with anticoagulant ethylene diamine tetra acetic acid (EDTA) and centrifuged to obtain plasma and this plasma was used for the estimation of plasma glucose (GOD/POD Method). Serum triacylglyceride (GPO/POD Method), serum cholesterol, and serum HDL levels were estimated at $22^{\text {nd }}$ day. On the $0^{\text {th }}, 8^{\text {th }}, 15^{\text {th }}$ and $22^{\text {nd }}$ day body weight of the animals were also recorded. (Ghaisas et al., 2009; Gholap \& Kar, 2005).

\section{Biochemical estimations}

Plasma concentration of glucose and serum concentration of cholesterol, triacylglyceride and HDL were estimated by using standard diagnostic kits from Biolabs India Ltd., India. LDL, VLDL and atherogenic index were calculated using the following formula: LDL $=$ Total cholesterol-triacylglyceride/5-HDL VLDL $=$ Triacylglyceride $/ 5$

Atherogenic index $=$ Total cholesterol/HDL cholesterol (Adebayo et al., 2011)

\section{Statistical analysis}

The results were expressed as mean \pm S.E.M. and statistically analyzed by using INSTAT software by ANOVA followed by Dunnett test. $p<0.05$ was considered statistically significant.

\section{Result and Discussion}

Ethanolic extract gave positive reaction for anthraquinone, cardiac and saponin glycosides, flavonoids, steroids, triterpenoids, carbohydrates and tannins. The TLC results showed the presence of two spots at $R_{f} 0.43$ and 0.46 as green spot and violet spot respectively for saponins, three spots at $R_{f} 0.28,0.84$ and 0.94 as pink, violet and violet spot respectively for triterpenoids and a single spot at $R_{f} 0.52$ as yellow fluorescence for flavonoids.

The isolated yellowish brown powder obtained, had a yield of $35 \%$, melting point $220-2220 \mathrm{C}$. The spectral data showed UV ${ }^{\mathrm{MeO}} \mathrm{H} \lambda_{\max }$ nm: 272 , FT-IR $\left(\mathrm{cm}^{-1}\right)(\mathrm{KBr})$ : 3209,3321, 2939, 1037, 1442, 1512, 1562, 1724, 1H NMR in $\mathrm{DMSO}_{-} \mathrm{d}_{6}(300 \mathrm{MHz})(\delta \mathrm{ppm}): 6.79(1 \mathrm{H}, \mathrm{d}, \mathrm{H}-2), 6.4$ (1H, t, H-3), 6.86 (1H, d, H-4), 7.16 (1H, s, H-5), 6.25 (1H, s, H-7), 8.76 (phenolic proton), 3.447-4.905 (sugar protons) DART-MS: spectra showed a molecular ion peak at $m / z 416.17\left[\mathrm{M}^{+}\right]$indicating molecular weight of 416 . It also showed peaks at $415.19[\mathrm{M}-\mathrm{H}+], 253.04$ (aglycone), 165.05 (glucose). From the above spectral studies the compound was thus interpreted to be chrysophanol-8-O$\beta$-D-glucopyranoside, an anthraquinone glycoside (1).<smiles>Cc1cc(O)c2c(c1)C(=O)c1cccc(OC3C(O)C(CO)OC(O)C(O)C3O)c1C2=O</smiles>

The acute toxicity study showed that the ethanolic extract of the leaves of $W$. fruticosa (WF) was found to be safe up to dose of $2000 \mathrm{mg} / \mathrm{kg}$. p.o. On the basis of this, doses 100, 200 and $400 \mathrm{mg} / \mathrm{kg}$ were selected for the study.

The results of the animal studies revealed that in Dexa control group there was significant increase in plasma glucose level $(p<0.01)$, serum triacylglyceride level $(p<0.01)$, serum total cholesterol $(p<0.01)$, serum VLDL $(p<0.01)$, serum LDL $(p<0.01)$, atherogenic index $(p<0.01)$ and significant decrease in serum HDL $(p<0.01)$ and body weight $(p<0.01)$ when compared to the normal control, this reveals the induction of hyperglycaemia and hyperlipidaemia. The mice treated with Dexa and pioglitazone showed significant decrease in plasma glucose level $(p<0.01)$, serum triacylglyceride $(p<0.01)$, total cholesterol $(p<0.01)$, serum VLDL $(\mathrm{p}<0.01)$, serum LDL $(p<0.01)$, atherogenic index $(p<0.01)$ and significant increase in serum HDL $(p<0.01)$ and body weight $(p<0.01)$. All mice treated with Dexa and WF also showed significant decrease in plasma glucose level $(p<0.01)$, serum triacylglyceride $(p<0.01)$, total cholesterol $(p<0.01)$, serum VLDL $(p<0.01)$, serum LDL $(p<0.01)$, atherogenic index $(p<0.01)$ (Table 1 and 2$)$ and significant increase in serum HDL $(p<0.01)$ and body weight $(p<0.01)$ (Table 3$)$, thus reveals the ability of $W$. fruticosa to reduce hyperglycaemia and hyperlipidaemia. The administration of WF at the dose of $400 \mathrm{mg} / \mathrm{kg}$ showed marginal hypoglycemia $(p<0.05)$ when compared to the normal control.

Excess of either endogenous or exogenous glucocorticoids has been shown to increase gluconeogenesis and decrease tissue glucose uptake thus resulting in hyperglycemia, potentially inducing diabetes. Different mechanism for corticosteroid induced diabetes mellitus have been postulated from time to time. One of those is the insulin resistance, caused by the alteration in binding of insulin to its receptor (receptor defect) or by the impairment of the intracellular response to insulin (post receptor defect) (Gholap \& Kar, 2005).

Tyrosine phosphatase $1 \mathrm{~B}$ has been implicated in insulin dependent pathways and in the insulin insensitivity, that is the most common pathology of type 2 diabetes and obesity. Tyrosin phosphatase $1 \mathrm{~B}$ acts to reverse tyrosine kinase action and is a key phosphatase for 
insulin receptor and insulin receptor substrate-1, major mediators of glucose transport pathways. Chrysophanol8-O- $\beta$-D-glucopyranoside (1) is reported to inhibit tyrosine phosphatase $1 \mathrm{~B}$ with IC50 values of $18.34 \pm 0.29$ $\mu \mathrm{M}$. Thus this reduction activity of tyrosine phosphatase $1 \mathrm{~B}$ could influence glucose transport activity through consistent phosphorylation on its specific substrate, the insulin receptor. Thus chrysophanol-8-O- $\beta$-Dglucopyranoside can be said to enhance insulin stimulated glucose transportation by insulin receptor activation. It has also been reported to prevent hyperglycemia associated diabetes through its mammalian intestinal $\alpha$-glucosidase inhibitory activity (Lee \& Sohn, 2008). The effect of ethanolic extract of Woodfordia fruticosa (WF) on blood glucose may be due to chemical constituent such as tannins, terpenoids, saponins and flavonoids reported to have antihyperglycemic effect (Matsudha et al., 2002; Kambouche et al., 2009; Sharma et al., 2008). Various compounds such as hecogenin, lupeol, oleanolic acid, ursolic acid, quercetin have also been isolated from $W$. fruticosa which enhances the importance of this plant.

As expected, in the present study, dexamethasone group showed reduction in body weight, while WF and pioglitazone treatment inhibited dexamethasone induced reduction in body weight and showed increase in body weight. The effect of WF on the body weight may be attributed to the increase in the sensitivity to insulin and the subsequent increase in the glucose uptake. Hyperlipidemia caused in diabetes is due to excess mobilization of fat from the adipose tissue is due to

Table 1. Effect of leaves of Woodfordia fruticosa on plasma glucose level in dexamethasone induced insulin resistance in mice.

\begin{tabular}{lcccc}
\hline \multirow{2}{*}{ Groups } & \multicolumn{4}{c}{ Plasma Glucose Level (mg/dL) } \\
\cline { 2 - 5 } & Day 0 & Day 8 & Day 15 & Day 22 \\
\hline NC & $53.71 \pm 0.15$ & $53.43 \pm 0.28$ & $53.67 \pm 0.71$ & $53.56 \pm 0.35$ \\
Dexa C & $54.03 \pm 0.15$ & $86.52 \pm 0.24^{\# \#}$ & $87.41 \pm 0.23^{\# \#}$ & $89.53 \pm 0.34^{\# \#}$ \\
Dexa+PIO & $53.86 \pm 0.16$ & $85.98 \pm 0.20$ & $69.35 \pm 0.19^{* *}$ & $56.42 \pm 0.15^{* *}$ \\
Dexa+WF 100 & $53.74 \pm 0.23$ & $87.47 \pm 0.13$ & $87.24 \pm 0.06$ & $82.58 \pm 0.62^{* *}$ \\
Dexa+WF 200 & $54.05 \pm 0.17$ & $87.18 \pm 0.36$ & $85.95 \pm 0.35^{*}$ & $75.04 \pm 0.99^{* *}$ \\
Dexa+WF 400 & $54.02 \pm 0.21$ & $87.45 \pm 0.30$ & $83.23 \pm 0.23^{* *}$ & $72.06 \pm 1.10^{* *}$ \\
PIO & $53.59 \pm 0.11$ & $53.59 \pm 0.09$ & $53.53 \pm 0.09$ & $53.43 \pm 0.08$ \\
WF 100 & $53.38 \pm 0.10$ & $53.59 \pm 0.15$ & $53.50 \pm 0.14$ & $53.25 \pm 0.11$ \\
WF 200 & $54.17 \pm 0.11$ & $53.77 \pm 0.13$ & $53.65 \pm 0.14$ & $53.18 \pm 0.15$ \\
WF 400 & $54.07 \pm 0.25$ & $53.76 \pm 0.23$ & $53.51 \pm 0.12$ & $52.70 \pm 0.14^{\#}$ \\
\hline Res
\end{tabular}

Results are presented as mean \pm SEM. $(\mathrm{n}=6)$, ANOVA followed by Dunnett's test; \#\# ( $p<0.01)$ when compared with normal control group; ${ }^{*} p<0.05$; ${ }^{* *} p<0.01$ when compared with dexamethasone control group. NC: Normal control group, received $0.9 \% \mathrm{w} / \mathrm{v}$ saline ( $\left.1 \mathrm{~mL} / \mathrm{kg}, p . o . / \mathrm{day}\right) ;$ Dexa C: Dexamethasone control group, received dexamethasone ( $1 \mathrm{mg} / \mathrm{kg}$, i.m./day), PIO: Pioglitazone ( $2 \mathrm{mg} / \mathrm{kg}$, p.o.); WF: Ethanolic extract of leaves of Woodfordia fruticosa $100,200,400 \mathrm{mg} / \mathrm{kg}$ p.o.

Table 2. Effect of leaves of Woodfordia fruticosa on total cholesterol, serum triacylglyceride, serum HDL, serum LDL, serum VLDL, and atherogenic index in dexamethasone induced insulin resistance in mice.

\begin{tabular}{lcccccc}
\hline \multicolumn{1}{c}{ Groups } & $\begin{array}{c}\text { Total cholesterol } \\
(\mathrm{mg} / \mathrm{dL})\end{array}$ & $\begin{array}{c}\text { Serum triacylglyceride } \\
(\mathrm{mg} / \mathrm{dL})\end{array}$ & $\begin{array}{c}\text { Serum HDL } \\
(\mathrm{mg} / \mathrm{dL})\end{array}$ & $\begin{array}{c}\text { Serum LDL } \\
(\mathrm{mg} / \mathrm{dL})\end{array}$ & $\begin{array}{c}\text { Serum VLDL } \\
(\mathrm{mg} / \mathrm{dL})\end{array}$ & $\begin{array}{c}\text { Atherogenic } \\
\text { index }(\mathrm{A} . \mathrm{I})\end{array}$ \\
\hline NC & $78.10 \pm 0.44$ & $80.68 \pm 0.15$ & $34.54 \pm 1.60$ & $27.41 \pm 1.57$ & $16.13 \pm 0.03$ & $2.27 \pm 0.09$ \\
Dexa C & $165.45 \pm 0.80^{\# \#}$ & $150.71 \pm 0.46^{\# \#}$ & $22.56 \pm 1.07^{\# \#}$ & $112.74 \pm 0.89^{\# \#}$ & $30.13 \pm 0.09^{\# \#}$ & $7.40 \pm 0.30^{\# \#}$ \\
Dexa+PIO & $113.13 \pm 2.88^{* *}$ & $88.14 \pm 0.32^{* *}$ & $31.06 \pm 1.02^{* *}$ & $65.90 \pm 4.10^{* *}$ & $17.62 \pm 0.06^{* *}$ & $3.90 \pm 0.30^{* *}$ \\
Dexa+WF 100 & $162.61 \pm 2.22$ & $148.71 \pm 0.56$ & $25.85 \pm 0.73$ & $107.01 \pm 2.42$ & $29.74 \pm 0.11$ & $6.31 \pm 0.20^{* *}$ \\
Dexa+WF 200 & $141.02 \pm 1.15^{* *}$ & $130.27 \pm 0.43^{* *}$ & $27.86 \pm 1.21^{*}$ & $87.10 \pm 1.38^{* *}$ & $26.05 \pm 0.08^{* *}$ & $5.10 \pm 0.22^{* *}$ \\
Dexa+WF 400 & $121.33 \pm 3.05^{* *}$ & $109.00 \pm 0.94^{* *}$ & $32.24 \pm 1.01^{* *}$ & $67.28 \pm 3.04^{* *}$ & $21.79 \pm 0.18^{* *}$ & $3.77 \pm 0.12^{* *}$ \\
PIO & $76.93 \pm 0.65$ & $80.46 \pm 0.66$ & $33.11 \pm 1.04$ & $27.72 \pm 1.06$ & $16.08 \pm 0.13$ & $2.32 \pm 0.07$ \\
WF 100 & $77.15 \pm 0.05$ & $80.19 \pm 0.34$ & $32.73 \pm 0.90$ & $28.37 \pm 0.94$ & $16.03 \pm 0.06$ & $2.36 \pm 0.06$ \\
WF 200 & $77.13 \pm 1.06$ & $80.07 \pm 0.53$ & $34.17 \pm 0.36$ & $26.94 \pm 0.82$ & $16.01 \pm 0.10$ & $2.25 \pm 0.02$ \\
WF 400 & $77.10 \pm 1.62$ & $81.41 \pm 0.31$ & $35.58 \pm 0.82$ & $25.23 \pm 1.86$ & $16.28 \pm 0.06$ & $2.16 \pm 0.07$ \\
\hline Rest & & & &
\end{tabular}

Results are presented as mean \pm SEM. $(\mathrm{n}=6)$; ANOVA followed by Dunnett's test, ${ }^{\#} p<0.01$ when compared with normal control group; $* p<0.05$, $* * p<0.01$ when compared with dexamethasone control group. NC: Normal control group, received $0.9 \% \mathrm{w} / \mathrm{v} \mathrm{saline}(1 \mathrm{~mL} / \mathrm{kg}, p . o . / \mathrm{day}) ; \mathrm{Dexa} \mathrm{C}$ : Dexamethasone control group, received dexamethasone (1 mg/kg, i.m./day); PIO: Pioglitazone (2 mg/kg, p.o.); WF: Ethanolic extract of leaves of Woodfordia fruticosa $100,200,400 \mathrm{mg} / \mathrm{kg}$ p.o. 
under utilization of glucose. Untreated diabetes causes hypertriglyceridemia and hypercholesteromia with the increase of LDL and VLDL which may lead to various health problems. Treatment with ethanolic extract of $W$. fruticosa (WF) decreased cholesterol, triacylglycerides, LDL, VLDL and increased HDL level, showed the effectiveness of WF to treat hyperlipidemia (Sen et al., 2010).
In conclusion, the ethanolic extract of the leaves of $W$. fruticosa at the dose of 100, 200 and $400 \mathrm{mg} / \mathrm{kg}$ was found to be effective in dexamethasone induced insulin resistance in mice and plant can be a future effective medicine for the treatment of diabetes, thus supports the traditional claim of the plant in treatment of diabetes. Further studies are infact underway to confirm the exact mechanism of action and isolation of other phytoconstitutents responsible for such activity.

Table 3. Effect of leaves of Woodfordia fruticosa on \% change in body weight in dexamethasone induced insulin resistance in mice.

\begin{tabular}{lccc}
\hline & \multicolumn{3}{c}{ \% Change in body weight } \\
\cline { 2 - 4 } & At day 8 & At day 15 & At day 22 \\
\hline NC & $0.72 \pm 0.72$ & $1.44 \pm 0.91$ & $1.44 \pm 0.91$ \\
Dexa C & $-9.62 \pm 0.93$ & $-17.13 \pm 0.63^{\# \#}$ & $-23.18 \pm 1.42^{\# *}$ \\
Dexa+PIO & $-8.76 \pm 0.11$ & $-2.17 \pm 0.97^{* *}$ & $0.75 \pm 0.75^{* *}$ \\
Dexa+WF 100 & $-5.61 \pm 2.97$ & $-5.61 \pm 2.97^{* *}$ & $-1.99 \pm 2.83^{* *}$ \\
Dexa+WF 200 & $-8.77 \pm 0.17$ & $-6.62 \pm 1.04^{* *}$ & $-2.23 \pm 1.00^{* *}$ \\
Dexa+WF 400 & $-11.11 \pm 2.93$ & $-6.85 \pm 3.00^{* *}$ & $-2.59 \pm 3.07^{* *}$ \\
PIO & $1.41 \pm 0.89$ & $0.72 \pm 0.72$ & $0.72 \pm 0.72$ \\
WF 100 & $2.20 \pm 0.98$ & $2.20 \pm 0.98$ & $2.20 \pm 0.98$ \\
WF 200 & $2.23 \pm 1.00$ & $2.23 \pm 1.00$ & $1.51 \pm 1.47$ \\
WF 400 & $1.38 \pm 0.87$ & $0.72 \pm 1.25$ & $-1.30 \pm 1.70$ \\
\hline
\end{tabular}

Results are presented as mean $\pm \mathrm{SEM} ; \mathrm{n}=6$; ANOVA followed by Dunnett's test, ${ }^{\#} p<0.01$ when compared with normal control group; ${ }^{*} p<0.05$; ${ }^{* *} p<0.01$ when compared with dexamethasone control group. NC: Normal control group received $0.9 \% \mathrm{w} / \mathrm{v}$ saline $(1 \mathrm{~mL} / \mathrm{kg}, p . o . / \mathrm{day}) ;$ Dexa C: Dexamethasone control group, received dexamethasone ( $1 \mathrm{mg} / \mathrm{kg}$, i.m./day); PIO: Pioglitazone (2 mg/kg, p.o.); WF: Ethanolic extract of leaves of Woodfordia fruticosa $100,200,400 \mathrm{mg} / \mathrm{kg}$ p.o.

\section{References}

Adebayo JO, Igunnu A, Arise RO, Malomo SO 2011. Effects of co-administration of artesunate and amodiaquine on some cardiovascular disease indices in rats. Food Chem Toxicol 49: 45-48.

Bhujbal SS, Nanda RK, Deoda RS, Sharma DK, Kewatkar SM, More LS, Patil MJ 2010. Structure elucidation of a newly isolated saponin from Clerodendrum serratum (L) Moon. Oriental Pharm Exp Med 10: 319-321.

Dan S, Dan SS 1984. Chemical examination of the leaves of Woodfordia fruticosa. J Indian Chem Soc LXI: 726727.

Ghaisas M, Navghare V, Takawale A, Zope V, Tanwar M, Deshpande A 2009. Effect of Tectona grandis Linn. on dexamethasone induced insulin resistance in mice. $J$ Ethnopharmacol 122: 304-307.

Gholap S, Kar A 2005. Gymnemic acids from Gymnema sylvestre potentially regulates dexamethasone induced hyperglycemia in mice. Pharm Biol 43: 192-195.

Goodman \& Gilman.A 2001. Insulin, Oral Hypoglycaemic agents and the pharmacology of endocrine pancreas. In The Pharmacological Basis of Therapeutics. $10^{\text {th }} \mathrm{ed}$.
McGraw-Hill, p. 1679-1714.

Jerald E, Joshi SB, Jain DC 2008. Diabetes and Herbal Medicines. Iran J Pharmacol Ther 7: 97-106.

Kambouche N, Merah B, Derdour A, Bellahouel S, Bouayed J, Dicko A, Younos C, Soulimani R 2009. Hypoglycemic and antihyperglycemic effects of Anabasis articulate (Forssk) Moq Chenopodiaceae), an Algerian medicinal plant. Afr J Biotechnol 8: 5589-5594.

Khandelwal KR 2004. Practical Pharmacognosy Techniques and Experiments. $12^{\text {th }}$ ed. Nirali Prakashan.

Klimek B, Tokar M 1998. Biologically active compounds from the flowers of Forsythia suspense Vahl. Acta Pol Pharm 55: 499-504.

Kunwar RM, Uprety Y, Burlakoti C, Chowdhary CL, Bussmann RW. 2009. Indigenous use and ethnopharmacology of medicinal plants in far-west Nepal. Ethnobotany Res Applications 7: 5-28.

Lee MS, Sohn CB 2008. Antidiabetic properties of Chrysophanol and its glucoside from Rhubarb rhizome. Biol Pharm Bull 31: 2154-2157.

Matsuda H, Morikawa T, Yoshikawa M 2002. Antidiabetogenic constituents from several natural medicines. Pure Appl Chem 74: 1301-1308. 
Nadkarni KM. 2009. Indian Materia Medica. Bombay Popular Prakashan.

OECD 2008. Guidelines for testing of chemicals 425. Acute oral toxicity-Up-and-Down procedure, p. 1-26.

Ramzi SC, Vinay Kumar, Tucker C 2000. Robbins Pathologic Basis of Disease. $6^{\text {th }}$ edition. Harcourt India Private Limited.

Sen S, Ganesh T, Thilagam E, Loganathan T, Chakraborty $\mathrm{R}$ 2010. Pharmacognostic and antihyperglycemic evaluation of Lantana camara (L) var. aculeate leaves in alloxan induced hyperglycemic rats. Int $J$ Res Pharm Sci 1: 247-252.

Sharma B, Viswanath G, Salunke R, Roy P 2008. Effects of flavonoid-rich extract from seeds of Eugenia jambolana
(L.) on carbohydrate and lipid metabolism in diabetic mice. Food Chem 110: 697-705.

Wagner H, Bladt S 2007. Plant Drug Analysis. A Thin Layer Chromatography Atlas. $2^{\text {nd }}$ ed., Springer Pvt Ltd.

Wild S, Roglic G, Green A, Sicree R, King H 2004. Global Prevalence of Diabetes, Diabetes Care 27: 1047-1053.

\section{*Correspondence}

Santosh S. Bhujbal

Department of Pharmacognosy, Padmashree Dr. D. Y. Patil Institute of Pharmaceutical Sciences and Research

Pimpri, Pune 411018, India

info.pharmacy@dypvp.edu.in

Tel. +919422022033 